\title{
Pharmacological Efficacy of Insulin-Loaded Granules Made Up of Various Grades of Hydroxypropyl Methylcellulose in Normal Rats
}

\section{Jasbir Singh ${ }^{1 *}$, Gajendra Singh ${ }^{1}$ and Harmeet Kaur ${ }^{2}$}

${ }^{1}$ College of Pharmacy, University of Health Sciences, Rohtak-124001, India

${ }^{2}$ Department of Pharmaceutical Sciences, Maharshi Dayanand University, Rohtak-124001, India

\begin{abstract}
The aim was to study the potential of various hydroxypropyl methylcellulose (HPMC) grades (K100LV, E50LV, E5LV, E4M, K4M and K100M) in enhancing oral bioavailability of insulin. Enteric coated insulin-loaded-HPMC granules were compared with peroral solution of zinc insulin in glycerine IP $(0.788 \mathrm{mg} / 0.2 \mathrm{ml})$. Since lowering of blood glucose levels (BGLs) was used as pharmacological response, the area above curve $\boldsymbol{A} \boldsymbol{A} \boldsymbol{C}_{0}^{24}$ was measured as a pharmacokinetic parameter instead of area under curve (AUC) for calculating bioavailability or pharmacological efficacy. In vitro studies showed that insulin release from granules was barred in acidic medium while almost complete release took place in basic medium upto $8 \mathrm{~h}$. In vivo studies in normal rats showed a maximum blood glucose reduction by K100LV based insulin-loaded granules, which corresponded to a relative pharmacological efficacy of $\sim 1.4 \%$ and absolute pharmacological efficacy of $\sim 0.5 \%$. In contrast, neither control granules nor control (peroral) solution showed a comparable effect. The multiple comparison post-hoc test, least square difference (LSD; at $p=0.05$ ), showed a significant difference of K100LV-, E50LV-, E5LV-, E4M- based insulin-loaded granules from placebo and of K100LV-, E50LV- based insulin-loaded granules from peroral solution. The potential of insulin-loaded HPMC granules followed a general order of K100LV > E50LV > E5LV > E4M > K4M > K100M in lowering of \% BGLs. Therefore, low viscosity grades of HPMC are efficient in enhancing oral insulin absorption as compared to high viscosity grades.
\end{abstract}

Keywords: Viscosity; Bioavailability; Efficacy; Area above curve; Dose; Oral granules

\section{Introduction}

The mucoadhesive polymers, if not targeted to colon may increase co-adherence of some drugs' fate to normal physiology through small intestine, which is most usual site for drugs absorption. The oral delivery of insulin to colon has been proposed to be a reason for promoting cancers as it by-passes liver, a major site of action of insulin. This also increases insulin's liability to be picked up by various precancerous and cancerous cells having abundance $(\sim 10$ times more as compared to normal cells) of insulin receptors or insulin-like growth factor receptors [1,2]. In normal physiology, insulin is secreted in small intestine, which enters into portal circulation and acts upon liver for controlling glucose metabolism. Any remaining fraction from liver thereafter enters into systemic circulation [3]. Therefore, if insulin is made to get absorbed from small intestine instead of targeting to colon, it may follow normal route of absorption and can act as per its normal physiology.

In present study the normal approach to protect insulin from acidic environment and enzymes by enteric coating and increasing residence time of granules by muco-adhesive polymers has been used for increasing bioavailability of insulin.

Many polymers like pectin, carbopols, polyvinyl alcohol (PVA), chitosan and its derivatives (with thiol groups) and various other mucoadhesives polymers have been used for increasing oral bioavailability of insulin [4-8]. The most successful among these polymers are chitosan derivatives, which have not been recognized as safe till date.

In the present work, the potential of well known, safe polymer, HPMC, was explored for oral insulin delivery. HPMC is known for its $\mathrm{pH}$ independent mucoadhesion and non-absorbable properties, which make it a good candidate for small intestine delivery if combined with enteric coatings of Eudragit ${ }^{\mathrm{TM}}(\mathrm{s})[9,10]$. Furthermore, its non-ionic nature does not pose any incompatibility problem with various drugs and proteins. As HPMC is available in various viscosity grades ranging from low to high viscosity, a plethora of opportunity is available for choice of grade for optimum insulin bioavailability.

The use of permeation enhancers [4] and/or enzyme inhibitors [11] was avoided to prevent side effects associated with their own absorptions, such as, systemic intoxications and/or hypertrophy and hyperplasia of the pancreas [8].

The oral administration of granules to normal rats was followed by determination of BGLs as pharmacological response. This is indirect approach of measuring pharmacological response instead of insulin concentration in blood. However, we have opted this methodology because; i) insulin concentration transitions in blood are not directly related with its pharmacological response; ii) pharmacological response of insulin is more important parameter in proving its therapeutic usefulness. Due to these reasons, blood glucose lowering was measured and related with insulin absorption. The bioavailability measured in this manner may be referred more appropriately as pharmacological efficacy [8].

\section{Methods}

Human zinc insulin suspension (Sigma Aldrich, India), HPMC grades (Table 1) (Methocel ${ }^{\mathrm{TM}}$, Colorcon Asia Pvt. Ltd., India) and Eudragit ${ }^{\mathrm{TM}} \mathrm{S}$ and L (Röhm Pharma, Germany) were used for insulin-

*Corresponding author: Jasbir Singh, College of Pharmacy, University of Health Sciences, Rohtak-124001, India, Tel: 01262-213202; E-mail: jasbirsinghsekhon@yahoo.co.in

Received June 30, 2015; Accepted August 22, 2015; Published August 29, 2015

Citation: Singh J, Singh G, Kaur H (2015) Pharmacological Efficacy of InsulinLoaded Granules Made Up of Various Grades of Hydroxypropyl Methylcellulose in Normal Rats. J Bioequiv Availab 7: 257-261. doi:10.4172/jbb.1000249

Copyright: ( 2015 Singh J, et al. This is an open-access article distributed under the terms of the Creative Commons Attribution License, which permits unrestricted use, distribution, and reproduction in any medium, provided the original author and source are credited. 
loaded granules preparation. Sugarchek ${ }^{\mathrm{TM}}$ glucometer (Wockhardt Ltd., India), Nichipette micro pipettes, Sartorius electronic balance LE324S were basic instruments used at various stages in research. Sieves no. $22(0.710 \mathrm{~mm}), 30(0.500 \mathrm{~mm})$ and $44(0.355 \mathrm{~mm})$ of BS standard and Blunt tip needles (No. 18; inner dia. $0.838 \mathrm{~mm}$ ) covered with siliconized oral feeding tube (No.6) of approx. 2.25 inches length were used for granulation and oral administration to rats. All other chemicals used were of analytical or higher grades.

\section{Preparation of granules and control solution}

The calculated quantities of insulin suspension and HPMC (single grade at a time) were mixed in multiples of single oral insulin dose as proposed in Table 2. The distilled water was added to facilitate wet granulation and granules were dried in air. After drying, granules were compressed into tablets by eccentric, single-punch tablet-making machine. The tablets were then crushed and granular mass was polished on a rotating pan of spheronizer to reduce sharp edges of granules. The polished granules were sieved through a set of 22-30-44 BS standard sieves. Thereafter, the granules between $30-40$ sieve set were enteric coated with 50:50 \% composition of Eudragit $L$ and Eudragit $S$ in a 3\% $\mathrm{w} / \mathrm{v}$ acetonic solution and air dried using laboratory developed fluid bed dryer at an air pressure of $0.8 \pm 0.2 \mathrm{Kg} / \mathrm{cm}^{2}$. Coating was continued until a theoretical weight increase of $20 \%$ was achieved. The enteric coated granules were again sieved through 30-40 sieve set to get final granules between $0.500-0.355 \mathrm{~mm}$ size for oral administration to rats. The procedure was repeated for preparing granules of other HPMC grades. The placebo granules were also prepared similarly without addition of insulin suspension.

The peroral solution for average $150 \mathrm{~g}$ rat was simply prepared by dissolving appropriate quantity of insulin suspension as per Table 2 in normal saline.

\section{Effect of granulation/ coating process}

The analytical technique as standardised by Singh and Singh [12] was used for insulin analysis. Insulin-loaded-HPMC granules equivalent to single dose of insulin were dissolved in appropriate quantity of phosphate buffer of $\mathrm{pH} 7.0$ to a final dilution of $100 \mathrm{x}$ times. The resulting solutions were analysed for area under absorbance units (AU) within a wavelength range of $224-290 \mathrm{~nm}$ at $1 \mathrm{~nm}$ interval. After applying equation ' $A U=-0.009+71.112 \times$ Conc.' the concentration of unit dose was calculated. The method was repeated in triplicate for insulin-loaded granules of all HPMC grades. The results were reported as mean \pm S.D. values.

\section{In vitro release studies}

Insulin-loaded-HPMC granules of only E5LV, K100LV, E4M and $\mathrm{K} 100 \mathrm{M}$ grades were subjected to in vitro dissolution studies covering the whole range of viscosity and substitution ratio of HPMCs. The granules' quantity equivalent to $450 \mathrm{IU}$ of insulin was tested in triplicate in $500 \mathrm{ml}$ dissolution medium of $\mathrm{pH} 1.2$ and buffer of $\mathrm{pH}$ 6.6 using a 6-stage USP Type-II (paddle) dissolution apparatus. The purpose was to check release of insulin in simulated gastrointestinal fluid (SGF) conditions of stomach and small intestine. The insulin release was reported as $\%$ release upto $8 \mathrm{~h}$.

\section{Preparation of i.v. and s.c. injections}

Intravenous (i.v.) and subcutaneous (s.c.) injections of human zinc insulin suspension served as positive controls for absolute and relative pharmacological efficacy. For i.v. injection, $1 \mathrm{IU} / \mathrm{kg}$ b.w. and for s.c. injection, $2.0 \mathrm{IU} / \mathrm{kg}$ b.w. of insulin were prepared to final makeup of $0.1 \mathrm{ml}$ in sterile $154 \mathrm{mM}$ phosphate buffered saline of $\mathrm{pH} 7.5$, which was previously filtered through G-1 sintered glass filter $(0.22 \mathrm{~m}$, Borosil, India).

\section{In vivo evaluation of granules}

The animal studies were approved by Institutional Animal Ethics Committee, PGIMS, Rohtak, India and adhered to the guidelines of lab animal care. Normal, white wistar rats of $150 \pm 10 \mathrm{~g}$ weight were purchased from approved source Hisar Agriculture University, Haryana. Rats were kept on overnight fast $(12 \mathrm{~h})$ prior to dosing and divided into 11 groups each consisting of 6 rats for in-vivo studies. Six groups were administered oral insulin-loaded-HPMC granules (each of different HPMC grade) at an insulin dose of $150 \mathrm{IU} / \mathrm{kg}$ b.w. Four other groups received s.c. dose, i.v. dose, peroral solution and placebo for relative, absolute references and controls. One untreated group was also kept as control (untreated) group. Blood samples were withdrawn from tail vein immediately prior to administration as $t=0 \mathrm{~h}$, and subsequently at 1.0, 2.0, 3.0, 4.0, 6.0, 8.0, 10.0 and $24 \mathrm{~h}$ intervals post administration. Additional samplings were done at $0.5 \mathrm{~h}$ interval for i.v. and s.c. doses to note their possibility of early pharmacological responses. The dosed rats were fasted for further $12 \mathrm{~h}$ and kept in cages with free access to water. BGLs were immediately measured using the blood glucometer (Sugar Check, Wockhardt, India) [8].

\begin{tabular}{|l|c|c|c|}
\hline \multicolumn{1}{|c|}{ HPMC grades } & Viscosity (Cps) & \%Methoxy+\%hydroxypropyl & \multicolumn{1}{|c|}{ Remark } \\
\hline E5-LV & 5 & $29.1 \%+7.7 \%$ & Low viscosity and medium substitution ratio grades \\
\hline E50-LV & 50 & $29.0 \%+8.5 \%$ & Low viscosity and medium substitution ratio grades \\
\hline $\mathrm{K}^{*} 100-\mathrm{LV}^{*}$ & 100 & $22.8 \%+9.6 \%$ & Low viscosity and low substitution ratio grade \\
\hline $\mathrm{K}^{*} \mathrm{M}^{*}$ & 4000 & $22.9 \%+8.3 \%$ & High viscosity and low substitution ratio grade \\
\hline $\mathrm{K}^{*} 100 \mathrm{M}^{*}$ & 100000 & $23.3 \%+10.8 \%$ & High viscosity and low substitution ratio grade \\
\hline $\mathrm{E}^{*} \mathrm{M}^{*}$ & $3000-5600$ & $28.8 \%+8.7 \%$ & High viscosity and medium substitution ratio grade \\
\hline
\end{tabular}

Note: \# Actual reported values by Colorcon Asia Pvt. Ltd, India for batches provided

Table 1: HPMC Grades used in studies.

\begin{tabular}{|c|c|c|c|}
\hline Ingredients & Uncoated insulin-loaded-HPMC granules & Uncoated Control granules (placebo) & Control (peroral) solution \\
\hline Insulin & $22.5 \mathrm{IU}$ & - & $22.5 \mathrm{IU}$ \\
\hline HPMC & $180 \mathrm{mg}$ & $180 \mathrm{mg}$ \\
\hline Glycerine IP & -- & -- & $0.2 \mathrm{ml}$ \\
\hline
\end{tabular}

Note: Oral insulin dose $=150 \mathrm{lU} / \mathrm{kg}$ b.w.

Table 2: Composition of single oral dose for $150 \mathrm{~g}$ rat. 
Since, lowering of BGLs was expected in response to insulin absorption, the area above curve $\left(A U C_{0}^{24}\right)$ was used as pharmacokinetic parameter for bioavailability or pharmacological efficacy calculations instead of area under curve $\left(A U C_{0}^{24}\right)$. The $\left(A U C_{0}^{24}\right)$ from BGLs was calculated for all insulin-loaded-HPMC granules using control (untreated) BGLs as baseline. The relative pharmacological efficacy of insulin was determined as per following formula:

$$
\left(\frac{\left(A A C_{0}^{24}\right)_{\text {oral }}}{\left(A A C_{0}^{24}\right)_{\text {s.c. }}} \times \frac{\text { s.c. dose }}{\text { oral dose }}\right) \times 100
$$

The absolute pharmacological efficacy was determined in a similar manner but using following formula:

$$
\left(\frac{\left(A A C_{0}^{24}\right)_{\text {oral }}}{\left(A A C_{0}^{24}\right)_{\text {i.v. }}} \times \frac{\text { i.v. dose }}{\text { oral dose }}\right) \times 100
$$

A general reference about above formulae can be found from work of Krauland et al. [8]. After calculations of pharmacological efficacies, all other relevant graphs and calculations were done on \%BGLs calculated by relating actual BGLs by respective $0 \mathrm{~h}$ blood glucose values on \%age basis in each case.

The difference between grades or their usefulness/similarity in producing response was decided on the basis of post hoc "least square difference (LSD)" test. The goodness of this test is in its ability to compare all groups simultaneously at a same time. The test was used to compare grades $v s$. grades and grades $v s$. controls for producing definite inference.

\section{Statistical and graphical interface}

For multiple comparisons, the LSD test was applied in SPSS 16.0.1. A p-level of 0.05 was considered as the minimal level of significance. For all other calculations Microsoft Office Excel 2010 was used and GraphPad Prism 5 software was used for plotting various graphs.

\section{Results and Discussion}

\section{Effect of ganulation/ coating process}

Table 3 shows the \% assay values for three random samples of insulin-loaded-HPMC granules. It is clear that the effect of granulation/ coating process was minimal on insulin. The relative standard deviation (RSD) was also less than $2.0 \%$ indicating good stability of insulin during granulation/coating process.

\section{In vitro insulin release studies}

The \% release of insulin from various insulin-loaded-HPMC granules have been shown in Figure 1. It is obvious that insulin was not released or release was very less in $\mathrm{pH} 1.2$ from all granules even upto $8 \mathrm{~h}$. This was due to enteric coating that might have prevented insulin release in acidic conditions. In contrast, the release of insulin gradually increased and reached $>85 \%$ during first $3.0 \mathrm{~h}$ for E5LV,
K100 LV and $~ 80 \%$ for E4M, K100M in pH 6.6 medium. All grades showed almost complete release upto last time point, i.e., 8h. Overall, the release profiles were not significantly different from each other in a particular $\mathrm{pH}$ medium at $\mathrm{p}$-level of 5.0\%.

The fast release of insulin from E5LV, K100LV compared to E4M, $\mathrm{K} 100 \mathrm{M}$ granules may be due to difference in viscosities of grades. The gel layer in former grades, due to low viscosity might have eroded and washed away easily, which was otherwise tough to get removed in high viscosity grades. These results are consistent to previous findings of various researchers for solid dosage formulations like pellets, tablets having higher concentrations of HPMCs [12,13].

\section{In vivo evaluation of granules}

To confirm the usefulness of HPMC in increasing oral bioavailability of insulin, insulin-loaded-HPMC granules were tested in-vivo in normal white wistar rats. The $\boldsymbol{A A C}_{0}^{24}$ values following i.v., s.c. injections/doses, controls and insulin-loaded-HPMC granules have been given in Table 4. Insulin given as control (peroral) solution did not show any effect and the \%BGLs were in accordance to the normal physiological fluctuations of rats untreated (Figure 2). Insulin-loaded-HPMC granules led to different strength of responses. There was significant to slight decrease in the \%BGLs (Figure 3) except K100M where almost no change was observed. Among various grades, lowering effect was maximum for K100LV $(76.333 \pm 2.582 \%$; mean \pm S.D. for $n=6)$ followed by E50LV and then E5LV. The E4M showed intermediary effect while K4M showed least effect. In all cases, the BGLs reached the initial level $100 \%$ of the initial or normal values upto $24 \mathrm{~h}$ after dosage administration.

The maximum and minimum relative pharmacological efficacies (mean \pm S.D.; $\mathrm{n}=6$ ) were found to be $1.399 \pm 0.138 \%$ for K100LV granules and $0.292 \pm 0.031 \%$ for $\mathrm{K} 100 \mathrm{M}$ granules. For peroral solution, the relative pharmacological efficacies were found equal to $0.040 \pm 0.024 \%$ against s.c. injection/dose. Similarly, the maximum and minimum absolute pharmacological efficacies (mean \pm S.D.; $\mathrm{n}=6)$ was $0.537 \pm 0.059 \%$ for $\mathrm{K} 100 \mathrm{LV}$ granules and $0.080 \pm 0.044 \%$ for $\mathrm{K} 100 \mathrm{M}$ granules as compared to i.v. injection/dose. The absolute pharmacological efficacy for peroral solution was only $0.029 \pm 0.021 \%$. The values of both relative and absolute pharmacological efficacies for HPMC grades have been given in Table 5. Thus, K100LV is 35 times more effective on relative basis and 18 times more effective on absolute basis as compared to peroral solution indicating potential of $\mathrm{K} 100 \mathrm{LV}$ in enhancing oral bioavailability of insulin. This relative efficacy of K100LV was comparable to that for thiolated chitosan [8], but 5.7 times less compared to P(MAA-g-EG) hydrogels. Nakamura et al. [14] the order of lowering of BGLs by various grades and peroral solution was observed as:

$\mathrm{K} 100 \mathrm{LV}>\mathrm{E} 50 \mathrm{LV}>\mathrm{E} 5 \mathrm{LV}>\mathrm{E} 4 \mathrm{M}>\mathrm{K} 4 \mathrm{M}>\mathrm{K} 100 \mathrm{M}>$ control (peroral) solution

\begin{tabular}{|c|c|c|c|c|c|}
\hline Sr. no. & Dilution factor $(\mathrm{ml})$ & $A U=-0.009+71.112 \times$ Conc $_{\#}$ & Predicted IU (IU/mI) & Dilution factor $\mathrm{x}$ IU/mI & $\$ \%$ Assay \\
\hline 1 & $10 \times 10$ & 15.718 & 0.221 & 22.116 & 98.5 \\
\hline 2 & $10 \times 10$ & 15.756 & 0.222 & 22.169 & 98.8 \\
\hline 3 & $10 \times 10$ & 16.183 & 0.228 & 22.770 & 101.5 \\
\hline Mean \pm S.D. & -- & -- & -- & -- & $99.6 \pm 1.6$ \\
\hline RSD & -- & -- & -- & -- & 1.6 \\
\hline
\end{tabular}

The post-hoc test, i.e., LSD for simultaneous group comparison was

Note: \# Laboratory developed standard equation.

\$ Label claim was $22.5 \mathrm{IU}$

Table 3: Granulation and coating processes effects on insulin 


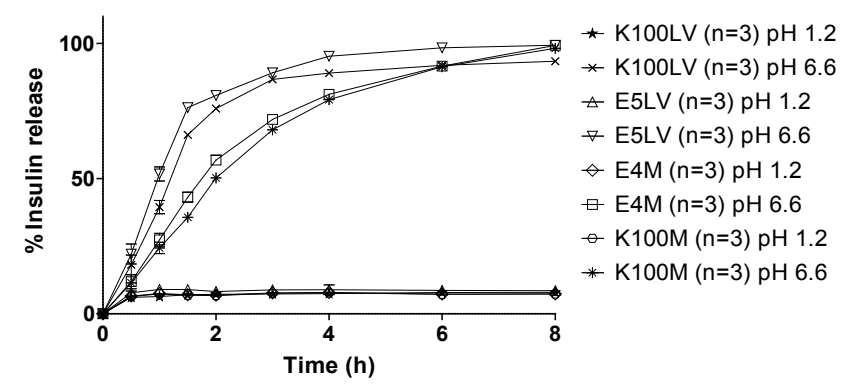

Figure 1: In vitro release profiles of insulin from various insulin-loaded-HPMC ganules.

\begin{tabular}{|l|l|l|}
\hline Groups & $\left(A A C_{0}^{\boldsymbol{\prime}} \pm S D\right)(\mathbf{N}=6)$ & RSD \\
\hline Peroral solution & $7.0 \pm 4.143$ & 60.633 \\
\hline i.v. injection & $190 \pm 94.998$ & 49.955 \\
\hline s.c. injection & $230 \pm 38.205$ & 16.581 \\
\hline K100LV & $242 \pm 23.763$ & 9.840 \\
\hline E50LV & $172 \pm 22.827$ & 13.259 \\
\hline E5LV & $155 \pm 21.520$ & 13.884 \\
\hline E4M & $95 \pm 9.268$ & 9.808 \\
\hline K4M & $53 \pm 12.436$ & 23.426 \\
\hline K100M & $50 \pm 5.324$ & 10.559 \\
\hline
\end{tabular}

Note: Control (untreated) was used as baseline BGLs for $A A C_{0}^{24}$ calculation

Table 4: Area above curve $\left(A A C_{5}^{* *}\right)$ values for insulin-loaded-HPMC granules and various references.

\begin{tabular}{|c|c|}
\hline Groups & \#\%Relative pharmacological efficacy (Mean \pm S.D.; $\mathbf{n = 6}$ ) \\
\hline Peroral solution & $0.040 \pm 0.024$ \\
\hline K100LV & $1.399 \pm 0.138$ \\
\hline E50LV & $0.988 \pm 0.132$ \\
\hline E5LV & $0.898 \pm 0.125$ \\
\hline E4M & $0.548 \pm 0.054$ \\
\hline K4M & $0.308 \pm 0.072$ \\
\hline K100M & $0.292 \pm 0.031$ \\
\hline
\end{tabular}

Note: Control (untreated) was used as baseline BGLs for $A A C_{0}^{24}$ calculation \#Relative pharmacological efficacy was calculated against s.c. injection \$Absolute pharmacological efficacy was calculated against i.v. injection

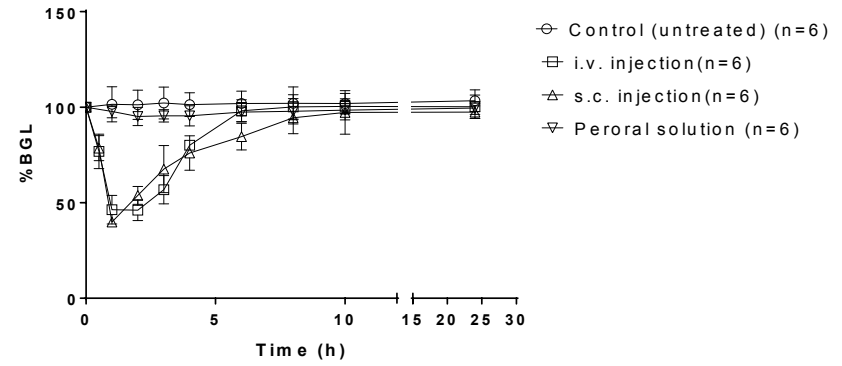

Figure 2: BGLs of untreated group and other reference groups.

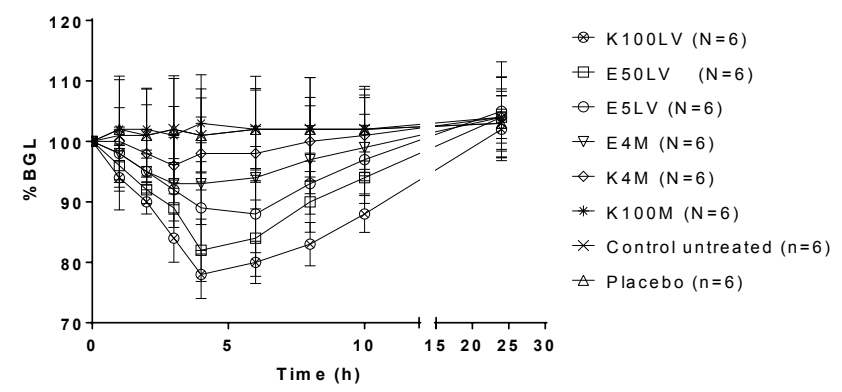

Figure 3: BGLs of placebo and insulin-loaded-HPMC granules of various grade.

Table 5: Pharmacological efficacy values for insulin-loaded-HPMC granules.

also applied on \% BGLs for determining similarity between grades and grade $v s$. controls. Table 6 is showing the mean difference values for grades $v s$. controls and grades. The values marked with asterisk mark are significantly different values at $p=0.05$. As per LSD, significant difference was found for K100LV-, E50LV-, E5LV-, E4M- granules from control granules and for K100LV-, E50LV- granules from both peroral solution and placebo. Thus, K100LV- and E50LV- significantly decreased BGLs that might have happened due to increased absorption of insulin. The E5LV- and E4M- also lowered BGLs but that lowering was not significantly different from the peroral solution. The K4Mand K100M- grades did not produce significant difference from even placebo. So, on an overall grade can be arranged on the basis of their efficiencies in reducing BGLs as:

\section{K100LV,E50LV > E5LV,E4M > K4M, K100M}

As per Table 6, the low viscosity grade, K100LV (when acted as primary group in comparison) was found significantly different from all grades, placebo and peroral solution except E50LV. The E50LV (when acted as primary group) was significantly different from all grades, placebo and peroral solution except K100LV and E5LV. In case of E5LV, similarity was found with E50LV, E4M, K4M and peroral solution. If in first comparison K100LV was maximum similar to E50LV (by significance value of 0.118 ) then in second comparison E50LV was maximum similar to E5LV (by significance value of 0.186 ) and in third comparison E5LV was maximum similar to peroral solution (by significance value of 0.317 ). Therefore, all these grades could be considered dissimilar to each other in producing responses.

The grades $\mathrm{E} 4 \mathrm{M}$ and $\mathrm{K} 4 \mathrm{M}$ were similar, since, both showed maximum similarity to peroral solution. The K100M showed maximum similarity to placebo. Among these grades, E4M showed strongest similarity to peroral solution, K100M showed maximum similarity to placebo, and K4M showed almost equal similarity to both peroral solution and to placebo. Since, these grades could not be considered equal to each other and were also not able to produce significantly different response from control(s), these are not ideal for increasing oral absorption of insulin. Therefore, the final order of HPMC grades may be cited as:

\section{$\mathrm{K} 100 \mathrm{LV}>\mathrm{E} 50 \mathrm{LV}>\mathrm{E} 5 \mathrm{LV}>\mathrm{E} 4 \mathrm{M}>\mathrm{K} 4 \mathrm{M}>\mathrm{K} 100 \mathrm{M}$}


Citation: Singh J, Singh G, Kaur H (2015) Pharmacological Efficacy of Insulin-Loaded Granules Made Up of Various Grades of Hydroxypropyl Methylcellulose in Normal Rats. J Bioequiv Availab 7: 257-261. doi:10.4172/jbb.1000249

\begin{tabular}{|c|c|c|c|c|c|c|c|c|}
\hline & K100LV & E50LV & E5LV & E4M & K4M & $\mathrm{K} 100 \mathrm{M}$ & Placebo & Peroral solution \\
\hline K100LV & -- & $3.546(0.118)$ & $6.536^{*}$ & $8.480^{*}$ & $10.695^{*}$ & $13.236^{*}$ & $13.053^{*}$ & $8.792^{*}$ \\
\hline E50LV & $-3.546(0.118)$ & -- & $2.990(0.186)$ & $4.934^{*}$ & $7.149^{*}$ & $9.690^{*}$ & $9.506^{*}$ & $5.246^{*}$ \\
\hline E5LV & $-6.536^{*}$ & $-2.990(0.186)$ & -- & $1.944(0.388)$ & $4.159(0.068)$ & $6.700^{*}$ & $6.516^{*}$ & $2.256(0.317)$ \\
\hline E4M & $-8.480^{*}$ & $-4.934^{\star}$ & $-1.944(0.388)$ & -- & $2.215(0.326)$ & $4.756^{*}$ & $4.573^{*}$ & $0.312(0.889)$ \\
\hline $\mathrm{K} 4 \mathrm{M}$ & $-10.695^{*}$ & $-7.149^{\star}$ & $-4.159(0.068)$ & $-2.215(0.326)$ & -- & $2.541(0.260)$ & $2.357(0.296)$ & $-1.903(0.398)$ \\
\hline K100M & $-13.236^{*}$ & $-9.690^{*}$ & $-6.700^{\star}$ & $-4.757^{*}$ & $-2.541(0.260)$ & -- & $-0.184(0.935)$ & $-4.444(0.051)$ \\
\hline Placebo & $-13.053^{*}$ & $-9.506^{*}$ & $-6.516^{*}$ & $-4.573^{*}$ & $-2.357(0.296)$ & $0.184(0.935)$ & -- & $-4.260(0.061)$ \\
\hline Peroral solution & $-8.792^{*}$ & $-5.246^{*}$ & $-2.256(0.317)$ & $-0.312(0.889)$ & $1.903(0.398)$ & $4.444(0.051)$ & $4.260(0.061)$ & -- \\
\hline
\end{tabular}

Note: 'Values in parenthesis are significance values. A value of $<0.05$ was considered significantly different as per SPSS 16.0 .1

Table 6: LSD results for various insulin-loaded-HPMC granules.

First three grades of HPMC in above order are low viscosity grades and last three grades are high viscosity grades. Therefore, it is not wrong to say that at low viscosity, HPMC increased oral bioavailability of insulin while at high viscosity it failed to improve oral insulin absorption. The effect of decrease in drug release with increase in polymer viscosity is already well known in various formulations [1522]. But the exact reason is difficult to spot, but it can be proposed that high viscosity grades might have resisted the easy dissolution/erosion of HPMC granules and out diffusion of insulin through granules.

\section{Conclusion}

As the low viscosity grades of HPMC featured efficient lowering of BGLs, the future drug delivery systems may be explored with these low viscosity grades of HPMCs. Further studies in polymer field with emphasis on viscosity and similar properties may result into simple and successful oral delivery systems for insulin.

\section{Acknowledgements}

We hereby acknowledge the help provided by Colorcon Asia Pvt. Ltd, India for providing various grades of HPMCs.

\section{References}

1. Belfiore A (2007) The role of insulin receptor isoforms and hybrid insulin/IGF-I receptors in human cancer. Curr Pharm Des 13: 671-686.

2. Li Y, Chang Q, Rubin BP, Fletcher CD, Morgan TW, et al. (2007) Insulin receptor activation in solitary fibrous tumours. J Pathol 211: 550-554.

3. Guyton AC (1987) Human Physiology and Mechanisms of Disease (4 $4^{\text {th }}$ Edn), Philadelphia, PA: WB Saunders Co: 595-604.

4. Damgé C, Vranckx H, Balschmidt P, Couvreur P (1997) Poly(alkyl cyanoacrylate) nanospheres for oral administration of insulin. J Pharm Sci 86: 1403-1409.

5. Hosny EA, Ghilzai NM, Elmazar MM (1997) Promotion of oral insulin absorption in diabetic rabbits using $\mathrm{pH}$-dependent coated capsules containing sodium cholate. Pharm Acta Helv 72: 203-207.

6. Bernkop-Schnürch A (2000) Chitosan and its derivatives: potential excipients for peroral peptide delivery systems. Int J Pharm 194: 1-13.

7. Bernkop-Schnürch A, Guggi D, Pinter Y (2004) Thiolated chitosans: development and in vitro evaluation of a mucoadhesive, permeation enhancing oral drug delivery system. J Control Release 94: 177-186.

8. Krauland AH, Guggi D, Bernkop-Schnürch A (2004) Oral insulin delivery: the potential of thiolated chitosan-insulin tablets on non-diabetic rats. J Control Release 95: 547-555.

9. Kotzé AF, Lueßen HL, de Leeuw BJ, de Boer AG, Verhoef JC, et al. (1998) Comparison of the effect of different chitosan salts and N-trimethyl chitosan chloride on the permeability of intestinal epithelial cells (Caco-2). J Control Release 51: 35-46.

10. Tiwari SB, Rajabi-Siahboomi AR (2009) Applications of complementary polymers in HPMC hydrophilic extended release matrices. Drug Delivery Technology 9: 20-27.

11. Yamamoto A, Taniguchi T, Rikyuu K, Tsuji T, Fujita T, et al. (1994) Effects of various protease inhibitors on the intestinal absorption and degradation of insulin in rats. Pharm Res 11: 1496-1500.

12. Campos-Aldrete ME, Villafuerte-Robles L (1997) Influence of the viscosity grade and the particle size of HPMC on metronidazole release from matrix tablets. Eur J Pharm Biopharm 43:173-178.

13. Patel VF, Patel NM (2007) Statistical evaluation of influence of viscosity and content of polymer on dipyridamole release from floating matrix tablets: a technical note. AAPS PharmSciTech 8: E69.

14. Nakamura K, Murray RJ, Joseph JI, Peppas NA, Morishita M, et al. (2004) Oral insulin delivery using P(MAA-g-EG) hydrogels: effects of network morphology on insulin delivery characteristics. J Control Release 95: 589-599.

15. Li S, Lin S, Daggy BP, Mirchandani HL, Chien YW (2003) Effect of HPMC and Carbopol on the release and floating properties of Gastric Floating Drug Delivery System using factorial design. Int J Pharm 253: 13-22.

16. Datar R, Rosen C (1990) Downstream process economics. In Asenjo JA, (Eds). Separation Processes in Biotechnology. New York and Basel: Marcel Dekker: 741-793.

17. Levinson S, Bhasker M, Gibson TR, Morin R, Snape WJ Jr (1985) Comparison of intraluminal and intravenous mediators of colonic response to eating. Dig Dis Sci 30: 33-39.

18. Phillips SF, Pemberton JH, Shorter RG, Talbot IC (1991) The large intestine: Physiology, pathophysiology and disease. New York, Raven Press: 141-168.

19. Rubinstein A, Tirosh B (1994) Mucus gel thickness and turnover in the gastrointestinal tract of the rat: response to cholinergic stimulus and implication for mucoadhesion. Pharm Res 11: 794-799.

20. Singh J, Singh G (2009) Area under absorbance curve vs. concentration for UV-spectrophotometric analysis of insulin in different $\mathrm{pH}$ conditions. Pharm Res 8: 70-75.

21. Snape WJ Jr, Matarazzo SA, Cohen S (1978) Effect of eating and gastrointestinal hormones on human colonic myoelectrical and motor activity. Gastroenterology 75: 373-378.

22. Wiley J, Tatum D, Keinath R, Chung OY (1988) Participation of gastric mechanoreceptors and intestinal chemoreceptors in the gastrocolonic response. Gastroenterology 94: 1144-1149. 